\title{
Unusual clinical presentation of stress fracture
}

\section{Abstract}

Bilateral stress fracture of fibula are very uncommon. We report an unusual case involving distal fibula in an 56-year-old woman and attributable to osteoporosis. Conservative treatement was followed by rehabilitation and the patient made a good recovery with no evidence of recurrence.

Keywords: Stress fracture, Fibula, Bilateral, Osteoporosis, Tumefactions, X-ray absorptiometry, Homogenous periostic reaction, Tomography, Hygienic advice, Physiotherapy, Richmond's theory, Bilateral distal stress, Bone density, Fractures, Lower extremity
Volume 7 Issue 6 - 2017

Khaled Zitouna,' Rim Dhahri, ${ }^{2}$ Maher Barsaoui,' Ghassen Drissi,' Elhem Cheour,' Mohamed Lassaad Kanoun'

'Departement Orthopedics and Traumatology, La Rabta Hospital, Tunisia

${ }^{2}$ Departement Rheumatology, La Rabta Hospital,Tunisia

Correspondence: Khaled Zitouna, Departement Orthopedics and Traumatology, La Rabta Hospital, rue Djebel Lakhdhar 1007, Tunis-Tunisia,Tel 00216989954 57;

Email kh.zitouna@laposte.net

Received: March 18,2017 | Published: April 13,2017

\section{Introduction}

Stress fracture of the Fibula is a well known lesion. It is often commonly described in dansers and runners. Some of its clinical findings features could be uncommon which could lead to a delay in of the diagnosis. These fractures usually tend to evolve favorably although some complications can occur.

\section{Case report}

A 56 year old woman, presents with bilateral algic supra malleolar tumefaction. The tumefactions appeared spontaneously and at the same time three months before. The patient did not have a history of smoking. She has been menopaused for five years and was overweight with a BMI at 28 .

Standard $\mathrm{x}$ rays revealed a poorly limited opacity englobed by a discrete sclerocele. There was a unilamelleolar homogenous periostic reaction Figure 1a. This opacity was located in the malleolar Fibula and was more important on the left side.

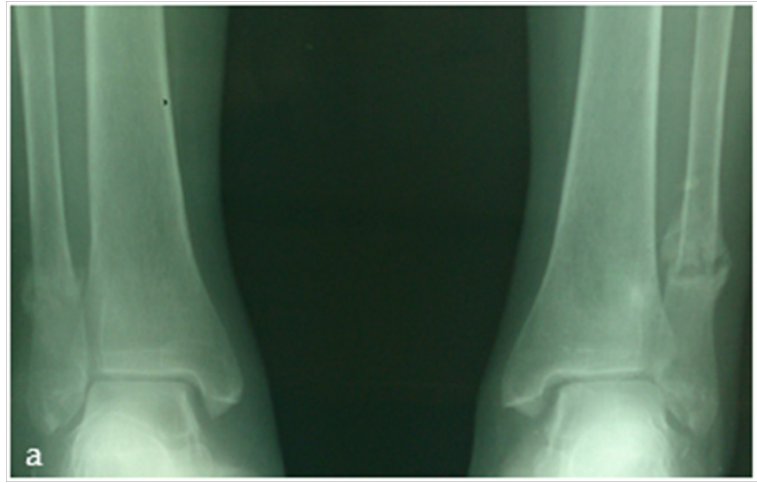

Figure Ia Radiograph of both ankles demonstrates a bilateral distal fibular opacity with periosteal reaction.

A computed tomography was performed to eliminate a neoplasic or infectious origine. It revealed a stress fracture with signs of consolidation at four $\mathrm{cm}$ from the apex Figure $1 \mathrm{~b}$.

Because of the age, the lack of history of sport activity, metabolic or genetic trouble modifying bone density, post-menopausal osteoporosis was highly suspected and later confirmed by Dual energy
X-ray absorptiometry $(0.852 \mathrm{gr} / \mathrm{cm} 2$ with T-score : -0.9 at the hip). Physical activity restriction, hygienic advice, medical treatment along with physiotherapy was initialized.

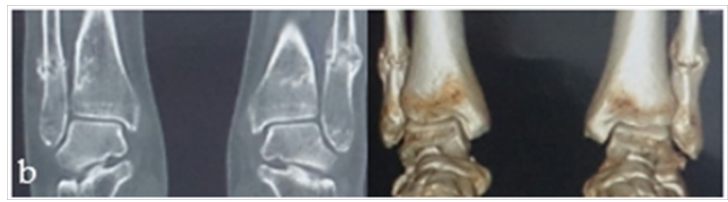

Figure Ib Computed tomography scan confirm the diagnosis of stress fracture.

Three years later, the patient has no ache or discomfort. Her range of walk is unlimited. X ray controls revealed signs of consolidation of the former fractures Figure 2.

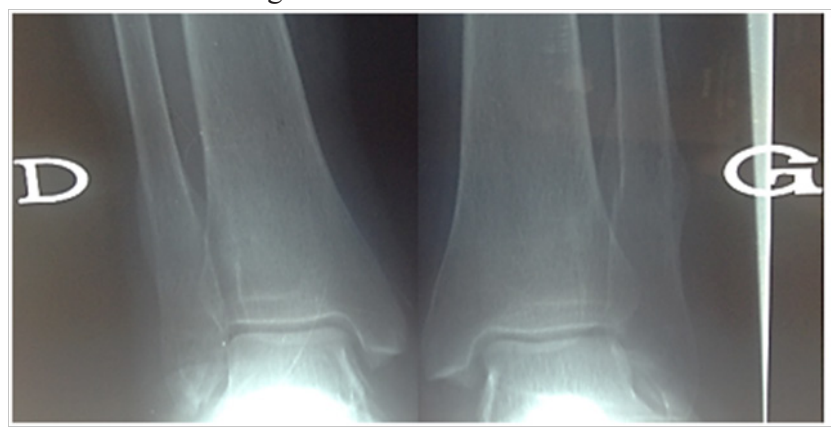

Figure 2 3-years radiograph control: bone healing of both fractures.

\section{Discussion}

Stress fracture of the malleolar fibula is a lesion that occurs essentially in athletes especially runners. Therefore it is called "Runner's fracture".

Burrows. ${ }^{1}$ in 1948 , was the first to publish about this subject. He classified them in two groups: First when the fracture line is located at 6-7 $\mathrm{cm}$ above the lower end of the Fibula. It occurs essentially in young male athletes. The second group included fractures in which the line is lower, at less than $3-4 \mathrm{~cm}$ from the tip. This type of fracture occurs most frequently in mid age women.

According to Burrows. ${ }^{1} \mathrm{X}$ ray findings start being visible three weeks after the clinical onset. Many theories have been advanced to 
explain the physiopathology of stress fractures. Richmond's theory. ${ }^{2}$ is that the continuous eversion of the foot especially in menopaused and obese women could be at the origin of the loss of external cortical continuity. This kind of fracture would be the result of opposite contemporary tractions : one towards the inside by interosseous ligaments and the other towards the outside of the malleolar while walking. Wang. ${ }^{3}$ on the other hand demonstrated that the Fibula receives 10 to $30 \%$ of the weight charge supported by the foot in the standing position. He suggested that, while in a walking position, stronger efforts tend to exagerate the charge over the distal part of the Fibula. This tension would be the cause of stress fractures. Devas et Sweetnam. ${ }^{4}$ blame the repetitive eccentric contractions of the plantar and long to flexors in combination with axial loading for proximal stress fractures.

The tension is at its outmost around the lower extremity of the Fibula which is the area of predilection for stress fractures. We believe these hypothesis complete each other.

The particularity of our observation is its aetiology and the fact that the fracture was bilateral. Matheson. ${ }^{5}$ estimated that only $16 \%$ of stress fractures are bilateral. Rare are the publications about this subject and none advanced an explanation for the double fracture. The use of new sports shoes. ${ }^{6,7}$ acute physical activity. ${ }^{8}$ the valgus of the ankles. ${ }^{9}$ coeliac disease. ${ }^{10}$ were incriminated by some authors, where as others find no explanation. ${ }^{11,12}$

We found that only kazimoglu. ${ }^{13}$ presented an observation similar to ours and links the stress fracture to osteoporosis. Known for its frequency in athletes and military staff, stress fractures could also concern menopaused women especially during the first period. In fact, as the bone density diminishes, an osteoporotic skeleton would be unable to resist to ordinary stress. The bone repairs its self from the multiple micro trauma's of repetitive stress. This capacity to remodel its self lessens with the age. ${ }^{13}$ Paradoxally, a long term treatment by Alendronate, a biphosphonate, anti-osteoporotic molecule, could cause stress fractures by changing the bone's architecture. ${ }^{14}$

All authors are in favor of a conservative treatment in case of bilateral lateral malleolar stress fracture.

The pneumatic brace has been shown to be efficacious in treating these fractures. The advantage of the brace over more conventional forms of treatment, such as casting, is that it allows immediate weight bearing, greater mobility for the patient, and allows periodic removal for hygiene. ${ }^{7}$ This treatment is reinforced by cryotherapy and physiotherapy. Because of the 3 month time between the clinical onset and the diagnosis, the $\mathrm{x}$ ray images (good bone callous), we preferred to substitute the activity restriction by a contention, and we also followed the patient on a regular basis.

\section{Conclusion}

Bilateral distal stress fracture of the fibula is very exceptional. Insufficiency fracture due to osteoporosis must be discussed when this lesion occur in a fifties sedentary woman.

\section{Acknowledgments}

None.

\section{Conflicts of interest}

None.

\section{References}

1. Burrows HJ Fatigue fractures of the fibula. $J$ bone Surg $B r$. 1948;30(2):266-279.

2. Richmond DA, Shafar J A case of bilateral fatigue fractures of the fibula. Br Med J. 1955;1(4908):264-265.

3. Wang Q, Whittle M, Cunningham J et al. Fibula and its ligaments in load transmission and ankle joint stability. Clin Orthop Relat Res. 1996 ;(330):260-271.

4. Devas MB, Sweetnam R Stress fractures of the fibulae. J Bone Joint Surg. 1956;38B(4):818-829.

5. Matheson GO, Clement DB, McKenzie DC et al. Stress fractures in athletes. A study of 320 cases. Am J Sports Med. 1987;15(1):46-58.

6. Anand S, Asumu T Bilateral distal fibula stress fracture in a young child. Injury. 2005;36:280-282.

7. Burgess I, Ryan MD Bilateral fatigue fractures of the distal fibula caused by a change of running shoes. Med J Aust. 1985;143(7):304-305.

8. Miller M, Marks PH, Fu FH Bilateral Stress Fractures of the Distal Fibula in a 35-Year-Old Woman. Foot Ankle int. 1994;15(8):450-453.

9. Tsuchiya H, Okada K, Nagasawa $\mathrm{H}$ et al. Bilateral stress fracture of the fibulae and periostitis of the tibia. Med Princ Pract. 2010;19(6):490-492.

10. Gilbody J, Trevett M Coeliac disease presenting with bilateral fibular stress fractures. Foot Ankle Surg 2009;15:96-100.

11. Tavakholizadeh A, Klinke M, Davies MS Bilateral distal fibular stress fractures. Foot Ankle Surg. 2005;11:171-173.

12. Hamilton AS, Finkelstein EH March fracture: report of a case involving both fibulae. J Bone Joint Surg Am. 1944;26:146-147.

13. Kazimoglu C, Karapinar H, Sener M et al. Bilateral stress fractures of the distal fibula in a woman with osteoporosis: a case report. $\mathrm{J} \mathrm{Am}$ Podiatr Med Assoc. 2009;99(1):61-64.

14. Goh SK, Yang KY, Koh JS et al. Subtrochanteric insufficiency fractures in patients on alendronate therapy. J Bone Joint Sugr Br. 2007;89(3):349-353. 